NBER WORKING PAPER SERIES

BALANCING THE GOALS OF HEALTH CARE PROVISION

\author{
Martin Feldstein \\ Working Paper 12279 \\ http://www.nber.org/papers/w12279
}

NATIONAL BUREAU OF ECONOMIC RESEARCH

1050 Massachusetts Avenue

Cambridge, MA 02138

May 2006

Professor of Economics, Harvard University, and President of the National Bureau of Economic Research. This paper is based on remarks presented at the meeting of the American Society of Health Economists session of the Allied Social Sciences Associations, Boston, Massachusetts, on January 7, 2006. Professor Feldstein is a director of Eli Lilly; HCA (Hospital Corporation of America), and American International Group. The views expressed herein are those of the author(s) and do not necessarily reflect the views of the National Bureau of Economic Research.

(C)2006 by Martin Feldstein. All rights reserved. Short sections of text, not to exceed two paragraphs, may be quoted without explicit permission provided that full credit, including $\mathbb{C}$ notice, is given to the source. 
Balancing the Goals of Health Care Provision

Martin Feldstein

NBER Working Paper No. 12279

May 2006

JEL No. I1, H2

\begin{abstract}
A desirable system for providing and financing health care would achieve three goals: (1) preventing the deprivation of care because of a patient's inability to pay; (2) avoiding wasteful spending; and (3) allowing care to reflect the different tastes of individual patients. Although it is not possible to realize fully all three of these goals, they can condition and inform the design of a good system for financing health care. This paper discusses the application of these goals in more detail and use them to consider a reform of the system of Health Savings Accounts that was enacted as part of the 2003 Medicare legislation and, separately, the challenge posed by the very expensive treatments for rare diseases that are becoming more common.

Martin Feldstein

National Bureau of Economic Research

1050 Massachusetts Avenue

Cambridge, MA 02138-5398

mfeldst@nber.org
\end{abstract}




\section{Balancing the Goals of Health Care Provision}

\section{Martin Feldstein*}

A desirable system for providing and financing health care would achieve three goals: (1) preventing the deprivation of care because of a patient's inability to pay; (2) avoiding wasteful spending; and (3) allowing care to reflect the different tastes of individual patients. In practice, however, it is not possible to realize fully all three of these goals. There are tradeoffs among them, as there generally are in every aspect of life. We can achieve one goal more fully only by a less complete achievement of one or both of the others.

But these goals should condition and inform the design of a good system for financing health care. In this paper, I will discuss the application of these goals in more detail and use them to consider a reform of the system of Health Savings Accounts that was enacted as part of the 2003 Medicare legislation and, separately, the challenge posed by the very expensive treatments for rare diseases that are becoming more common.

The ability of insurance to reduce the financial risk that individuals face

*Professor of Economics, Harvard University, and President of the National Bureau of Economic Research. This paper is based on remarks presented at the meeting of the American Society of Health Economists session of the Allied Social Sciences Associations, Boston, Massachusetts, on January 7, 2006. Professor Feldstein is a director of Eli Lilly; HCA (Hospital Corporation of America), and American International Group. 
while at the same time it increases the total cost of health care is central to the conflict among these three goals. Although most families consume a relatively small amount of health services in a typical year, a small fraction of families experience one or more spells in hospital and therefore consume very expensive health care. For most such individuals, the high cost of health care cannot be predicted in advance. This leads to the use of insurance to finance such bills.

An important feature of insurance is that it drives a wedge between the cost of producing care and the cost to the patient at the time that care is rendered. Since insurance means that patients generally pay only a small fraction of the cost of the care at the time that they receive the care, patients naturally want a substantially higher level of spending than they would if they were not insured. This is true even for moderate health events and for affluent individuals. Insurance raises health care spending not because it makes it possible for people to pay large health care bills (although it does that) but because it reduces the cost of health services relative to other goods and services that individuals consume.

So the widespread use of insurance is desirable because of the financial risks that result from the inherently skewed distribution of total costs per patient. But insurance is also damaging because it leads patients and their doctors to choose excessive levels of care, i.e., to increase spending to a level at which the last 
dollars' worth of care costs substantially more to produce than the value of that care to the patient's health. It is natural therefore to ask: What design of health insurance would best balance these two effects?

The finance of health care is also complicated by the fact that many people now have no health insurance. Because we as a society do not want people to go without care because they cannot afford to pay for it, the government steps in to provide free care for large groups of the population and to subsidize insurance for many others. What form should that government intervention take in light of the three goals?

A new problem for health care finance is emerging because of the breakthroughs in pharmacology and biogenetics. The resulting new drugs make it possible, but sometimes very expensive, to treat some diseases that were previously not treatable or not treatable with as high a probability of success.

Should private insurance cover such expensive treatments? Should such coverage be mandatory? If it is not, should the government pay the bill?

Preventing the deprivation of care

The goal of preventing the deprivation of care because of an inability to pay does not mean that care must be free for all. Although free care would achieve that 
goal, it would conflict strongly with the goal of avoiding wasteful spending.

Fortunately, most people can pay for small and medium size health bills

without any financial stress. It is the very large bills that can be a barrier to care for many people and a serious financial burden. That's why health insurance especially some form of major risk insurance - makes sense.

Even the extremely expensive care for some forms of cancer and certain other diseases that have been made possible by new forms of drug therapy is sufficiently rare that the insurance premiums required to pay for the actuarially expected cost of such care is not likely to be large relative to individuals' incomes. A treatment that costs $\$ 100,000$ but that is medically useful for only one person in 100,000 per year only increases the actuarial cost and therefore the needed insurance premium by one dollar per person per year. Such high costs of treatment appear in news stories when the individual's insurance policy does not cover these expenses, despite the low actuarial cost of doing so.

Pharmaceutical research is, of course, likely to increase the number of diseases that can be treated effectively but at high expense, adding to these actuarial costs. But at the same time pharmaceutical research is working on developing ways of identifying which patients can benefit from each type of treatment. These developments in targeted pharmacology will reduce the number 
of ineffective treatments and will thus reduce the cost of insurance. Targeted pharmacology should also reduce the cost of drug development (by reducing the sizes of the samples needed to prove efficacy), thus lowering the cost of the drugs themselves.

But there will inevitably be treatments that are very expensive and yet have a low probability of success. Avoiding deprivation of care because of an inability to pay does not mean providing every possible treatment, regardless of how low the probability of success. At a certain point, we would all agree that level of cost of such treatment would violate the second goal of avoiding wasteful spending.

Moreover, individuals differ in their willingness to pay through insurance for treatments that have a very low probability of success, even if the incremental premium is relatively low. That's why it is important to allow care to reflect differences among individuals in preferences, a subject to which I will return below.

\section{Avoiding Wasteful Spending}

Before doing so, I turn to the important goal of avoiding wasteful spending. There is widespread concern about the fact that health care spending has increased much more rapidly than GDP or personal incomes. It is important, however, to 
recognize that this rise in health care spending is not the same as an increase in the price of health care. The important difference is that the rise in spending is on new types of care rather than higher prices for the old type of care. Treatments have changed and become more effective. For many conditions, the cost of effective treatment has actually gone down because treatments are now more likely to be successful or because hospitalization has become unnecessary or because hospital stays have shortened. And even for those conditions for which the cost of success has gone up, I would much rather be a patient now than 10 or 20 years ago.

Estimates by my Harvard colleague David Cutler and others indicate that the value of the improved health over the past several decades has exceeded the increased cost of health care. But while that is true for the overall cost of care, it is not likely to be true for incremental care at the margin. There have been inframarginal gains in health and in the efficacy of health care but the structure of current insurance means that at the margin we are undoubtedly spending more for care than the value to patients of the resulting health improvements.

If patients and their doctors increase spending until the value to the patient of the "last dollar" of that care is equal to the additional net cost to the patient at the time of that care - i.e., to the cost net of insurance - then the system is providing care that, at the margin, costs a dollar but is valued by the patient at only (say) 20 
cents or whatever the coinsurance rate may be. When physicians are required by insurance rules or HMO regulations to choose a standard of care that more closely reflects the total cost of the incremental unit of care, they create frustrated patients who feel (correctly) that they are being denied care that could help them.

What is the solution to this problem? Part of the solution is some form of major risk insurance in which patients have a large deductible or high coinsurance rate. ${ }^{*}$ A deductible of $\$ 5,000$ - which is less than 10 percent of median family cash income - would leave most families paying for all of their health care out of pocket with no insurance reimbursement. Their decisions about the desired standard of care would therefore not be distorted by insurance. And while no one would welcome a medical bill for the year as large as $\$ 5,000$, most families would also not be deprived of care by an inability to pay since their maximum annual payment under the deductible would be less than 10 percent of family income. The same principle would lead to lower deductibles for families with lower incomes. Special rules could apply to preventive measures that are shown to be cost-effective or to procedures that reduce contagious diseases.

*I proposed such a form of insurance in "xxxxxxxxxxxxx," The Public Interest, $x x x x$ 19xx. Jonathan Gruber and I examined such a plan in "A New Approach to National Health Insurance," The Public Interest, Spring 1971. Jonathan Gruber and I examined such a plan empirically in Martin Feldstein and Jonathan Gruber, "A Major Risk Approach to Health Insurance Reform," in Tax Policy and the Economy, James Poterba (ed.) (Cambridge, MA: MIT Press, 1995) 
But a significant fraction of families - and a much larger fraction of health care spending - would exceed a $\$ 5,000$ deductible. With no out of pocket payment above that level, or only a modest coinsurance rate, there would be both wasteful spending and, to the extent that physicians restrict what patients would otherwise want, patient frustration as well.

Raising the deductible to, say, $\$ 10,000$ would reduce the problem of wasteful spending but would clearly create a substantial financial burden for many households and a barrier to appropriate care for some.

The goals of limiting wasteful spending and preventing the deprivation of care because of a financial burden might be better served by replacing the deductible with a high coinsurance rate. For example, instead of a $\$ 5,000$ deductible, the insurance policy might take the form of a 50 percent coinsurance rate on the first $\$ 10,000$ of spending. Patients would still be protected against paying more than $\$ 5,000$ out of pocket. But with a 50 percent coinsurance rate on $\$ 10,000$ of spending, there would be fewer patients and fewer dollars that face no out of pocket cost.

A constant 50 percent coinsurance rate on the first $\$ 10,000$ of costs may not be the best structure for the insurance policy. Determining that requires more analysis than I have done. It would depend on the distribution of potential 
spending levels, the sensitivity of spending to different coinsurance rates, and the value that individuals place on limiting their out of pocket cost of health care. In principle, the optimal policy might involve a combination of deductibles and different coinsurance rates for different ranges of spending. The deductibles and coinsurance rates might also be related to the income of the family.

\section{$\underline{\text { Health Saving Accounts }}$}

There is a lesson in this for the possible reform of Health Savings Accounts. I am an enthusiastic supporter of the Health Saving Account principle. I think however that it could be improved significantly and that failure to improve it might lead to its eventual rejection by the political process

The rules creating the Health Saving Account program were enacted as part of the 2003 Medicare legislation. A Health Saving Account is similar to an IRA or 401(k) in that funds are deposited out of pretax income (by the individual or a combination of the individual and his or her employer) and enjoy the advantage that the income of the account (interest, dividends and capital gains) accumulates tax free. Even better than an IRA or 401(k) account, the funds that are withdrawn from a Health Saving Account to pay for health care broadly defined are never 
subject to tax. The balance in the fund is carried forward just as an IRA would be."

The amount of money that can be deposited in a Health Saving Account each year is equal to the size of the deductible in a major risk insurance policy that the individual chooses, up to a maximum in 2006 of $\$ 5,450$. The policy must also provide protection by setting a maximum out of pocket amount that is incurred by coinsurance payments above the deductible. For 2006, this maximum out of pocket amount for a couple is $\$ 10,200$. A typical HSA policy might have a $\$ 5,000$ deductible and then a 20 percent copay until the total out of pocket spending reaches (say) $\$ 10,000$.

The tax advantage of the HSA account thus provides a strong incentive for individuals and employers to shift away from the current common type of health insurance policy with a low deductible and low coinsurance rate. Such traditional policies substantially distort the choice of care but provide a very significant tax benefit to the individual. The HSA option provides an opportunity to enjoy a similar or larger tax advantage by buying an alternative form of health insurance that provides financial protection while reducing the incentives that lead to wasteful spending. Individuals could use the HSA balances to spread their

*The HSA rule is therefore different from the earlier Medical Saving Accounts in which funds not spent within the year are not carried forward but are kept by the employer. Since there is no carry forward, there is no investment in Medical Saving Accounts. 
uninsured expenses (i.e., the expenses up to the deductible amount plus the coinsurance payments up to the maximum out of pocket limit) over time or they could treat their HSA as a type of IRA, paying the uninsured expenses out of pocket, and enjoying the maximum tax free accumulation of funds.

There are however two problems with the HSA legislation in its current form. First, the $\$ 5,450$ maximum deductible will leave far too many dollars of health spending without an effective restraint. As I noted above, it would be more effective in controlling costs to have a 50 percent coinsurance rate on $\$ 11,000$. Other combinations might be even better but a 50 percent coinsurance rate on $\$ 11,000$ is easy to understand.

The HSA approach will only succeed if individuals find it attractive. For lower income families, the risk of a $\$ 5,450$ deductible (or of out of pocket payments of 50 percent on the first $\$ 11,000$ of health spending) might be larger than they are willing to accept. Under the HSA rules, such a family could select a policy with a lower deductible and put less money into their Health Saving Account. A family with an income of $\$ 30,000$ could decide to have a deductible of only $\$ 3,300$ and therefore put only $\$ 3300$ into their HSA (including their employer's contribution). With a deductible of only $\$ 3,300$ such a family would be even more likely to spend above the deductible amount, removing any effective 
discipline on such spending. It would be better to allow such a family to deposit $\$ 3,300$ to an HSA if they have a policy with a 30 percent coinsurance rate on $\$ 11,000$ of spending. Although there must be a lower limit on the coinsurance rate to make sure that it has a favorable incentive effect, a 100 percent coinsurance rate (i.e., a deductible) on a low amount is certainly wrong.

The second problem with the HSA legislation in its current form is suggested by the fact that hospitals all across the country are experiencing a significant volume of bad debts caused by patients who do not pay their hospital bills after receiving care. This is particularly true for uninsured patients, but it is also true for insured patients who do not pay the coinsurance and deductibles called for by their policies.

Such nonpayments could become much more severe with Health Saving Accounts. An individual with a $\$ 5,000$ deductible may not have cash on hand to pay the bill when he is discharged from the hospital. While many individuals would accept the obligation and pay the bill promptly after that, perhaps by drawing on their Health Saving Account, others may simply put off payment and eventually not pay.

The advantage of the out of pocket payment as a discipline on excessive spending would of course be lost if individuals simply do not pay the deductible or 
copayment. The impact on the financial soundness of hospitals of not collecting the first $\$ 5,000$ of each hospital bill would be very serious.

One simple remedy for this would be to allow hospitals (and other health care providers) to have easy access to the HSA balances of individuals who have not paid within (say) three months of the time of care. This might be arranged through the insurance provider or by using an HSA debit card as collateral at the time of care. It is important to the attractiveness of the HSA system to allow individuals the choice of paying out of pocket if they prefer rather than from their HSA account. But easy access to the HSA accounts by providers without the usual legal procedure of collecting bad debts would be desirable in itself and a strong incentive for individuals to pay their bills.

\section{Allowing Health Care to Reflect the Different Tastes of Individual Patients.}

It was not too many years ago that a physician could make decisions about medical care by asking himself what would produce the very best health outcome for his patient. Economists, myself included, argued that that was not good enough and that doctors should take the cost of care into account, performing an implicit cost-benefit analysis to decide what care was appropriate. The rise in the cost of care, especially the cost of hospital inpatient care, brought about that change in 
physicians' thinking. Under pressure from hospital administrators and insurance companies, doctors developed protocols of appropriate care that reflected costs as well as outcomes.

Unfortunately, this approach has generally led to "one size fits all" medicine. A doctor generally prescribes the same treatment for demographically similar patients who have a particular disease or who present with particular symptoms. Of course, doctors differ in their perception of the efficacy of different treatments or diagnostic procedures and that leads to different behavior among different doctors. But, with certain important exceptions, the preferences of the patients do not play a significant role in this process. Those exceptions, for example the treatment of prostate cancer or breast cancer, are generally about balancing risks and other outcome measures and not balancing costs and outcomes.

And yet for every other kind of good or service, we assume that an important function of the market is to reflect differences in consumers' preferences. Of course, everyone wants good health. But some are more willing to make greater sacrifices to achieve that good health than others. This is not just a question of money or ability to pay. We all know that health is hurt by smoking, by being overweight, and by not exercising. And yet millions of Americans smoke, are overweight, and do not exercise. These habits may be hard to change but millions 
have changed them. So addiction is not an excuse. It seems reasonable to conclude that some individuals enjoy smoking enough to accept the potentially adverse long-term health effects. Ditto for food. And for not exerting themselves.

We should not be surprised therefore if taste differences about health also imply that some individuals are willing to pay more in order to get better health outcomes. This may involve paying more for more complete routine checkups, or for more complete diagnostic examinations when there are symptoms, or for more expensive care of adverse medical conditions (either at the time of care or in the choice of a particular insurance policy or HMO plan.).

How does this fit with the other goals of health care provision - preventing the deprivation of care and avoiding wasteful spending? For patients whose spending is within a deductible limit, there is no conflict. If their physician and hospital are willing, they can buy whatever they want and are willing to pay for. It would certainly be a mistake to prevent them from doing so.

An advantage of the high coinsurance rate is that individuals can indicate their preference by willingness to pay. They may of course be paying only 50 cents to buy care that costs a dollar to produce, suggesting that it would be appropriate for the provider to exercise some restraint on what they buy. But reflecting individual preferences implies that should not be done to the point where all 
individuals are forced to accept the same care.

The problem is more difficult when the coinsurance rate is at a low level or when the patient is not paying at all. Under those circumstances, there is no way to know patient's preferences and the physician and institutional provider must determine what the patient gets. But that should be seen as an undesirable outcome, denying patients and their physicians the opportunity to adjust care to different preferences. That suggests that it would be desirable to design the financing system to avoid such situations. That might involve, for example, arrangements in which patients express their preferences by the type of coverage they select or the style of the Health Maintenance Organization (HMO) that they join. Even if they are not paying out of pocket at the time of care, they can express a desire for more complete preventive care or diagnostic exams or form of treatment by the selection among different policies or different HMOs.

This could also be the framework for solving the problem of the very expensive treatments that are now becoming possible. There are some treatments that physicians (and patients if they knew enough) would agree should always be done even though they are very expensive because they produce favorable outcomes with high enough probability relative to the cost of the treatment. Unless such treatments are required to be part of every standard health insurance policy (or 
are covered by a government catastrophic risk plan), there would be a temptation for some individuals to reduce their insurance premiums by selecting insurance without such coverage in the knowledge that society would pay for the care if they met the medical conditions. Those are the policies that generate the news stories now about "impossibly expensive" forms of care.

But for those treatments that are more questionable - offering lower probabilities of success or only small increases in life expectancy in exchange for very large costs - individuals could have the discretion in advance when they buy insurance or choose an HMO plan. Just as some insurance plans now include a wider range of drugs than other plans, the same could be applied to the very expensive treatments for various diseases. How this is to be done in practice and what its consequences are for the cost of care remain an important challenge for the future.

\section{$\underline{\text { Conclusion }}$}

In summary, the design of health care financing involves balancing three goals: preventing the deprivation of care, avoiding wasteful spending, and allowing care to reflect the different tastes of individual patients. The trade-offs among these three goals is changing as the cost and potency of care increases.

The system of Health Saving Accounts provides a new framework within 
which to balance these goals but requires modification if it is to strengthen incentives and avoid increasing the bad debt problem of hospitals and doctors.

January 2006

Revised: May 2006 